in 5-year-old children. Am. J. Respir. Crit. Care Med. 174:499-507.

6. Devereux, G., et al. 2007. Maternal vitamin D intake during pregnancy and early childhood wheezing. Am. J. Clin. Nutr. 85:853-859.

7. Chatzi, L., et al. 2008. Mediterranean diet in pregnancy is protective for wheeze and atopy in childhood. Thorax. 63:507-513

8. Calvani, M., et al. 2006. Consumption of fish, butter and margarine during pregnancy and development of allergic sensitizations in the offspring: role of maternal atopy. Pediatr. Allergy Immunol. 17:94-102.

9. Willers, S.M., et al. 2008. Maternal food consumption during pregnancy and the longitudinal development of childhood asthma. Am. J. Respir. Crit. Care Med. 178:124-131.

10. Kramer, M.S., and Kakuma, R. 2006. Maternal dietary antigen avoidance during pregnancy or lactation, or both, for preventing or treating atopic disease in the child. Cochrane Database Syst. Rev. 3:CD000133.

11. Rastogi, D., et al. 2007. Antigen-specific immune responses to influenza vaccine in utero. J. Clin. Invest. 117:1637-1646.

12. Chung, E.K., Miller, R.L., Wilson, M.T., McGeady, S.J., and Culhane, J.F. 2007. Antenatal risk factors, cytokines and the development of atopic disease in early childhood. Arch. Dis. Child Fetal Neonatal Ed. 92:F68-F73.

13. Sicherer, S.H., and Burks, A.W. 2008. Maternal and infant diets for prevention of allergic diseases: understanding menu changes in 2008. J. Allergy Clin. Immunol. 122:29-33.

14. Miller, R.L., and Ho, S. 2008. Environmental epigenetics and asthma: Current concepts and call for studies. Am. J. Respir. Crit. Care Med. 177:567-573.

15. Cooney, C.A., Dave, A.A., and Wolff, G.L. 2002. Maternal methyl supplements in mice affect epigenetic variation and DNA methylation of offspring. J. Nutr. 132:2393S-2400S.

16. Waterland, R.A., and Jirtle, R.L. 2003. Transposable elements: Targets for early nutritional effects on epigenetic gene regulation. Mol. Cell. Biol. 23:5293-5300.

17. Dolinoy, D., Weidman, J., and Jirtle, R. 2007. Epigenetic gene regulation: linking early developmental environment to adult disease. Reprod. Toxicol. 23:297-307.

18. Tang, W., and Ho, S.M. 2007. Epigenetic reprogramming and imprinting in origins of disease. Rev. Endocr. Metab. Disord. 8:173-182

19. Li, Y.-F., Langholz, B., Salam, M.T., and Gilliland, F.D. 2005. Maternal and grandmaternal smoking patterns are associated with early childhood asthma. Chest. 127:1232-1241.

20. Liu, J., et al. 2008. Combined inhaled diesel exhaust particles and allergen exposure alter methylation of $\mathrm{T}$ helper genes and IgE production in vivo. Toxicol. Sci. 102:76-81.

21. Yang, Y., et al. 2008. Epigenetic mechanisms silence a disintegrin and metalloprotease 33 expression in bronchial epithelial cells. J. Allergy Clin. Immunol. 121:1393-1399.

22. Ito, K., et al. 2002. Expression and activity of histone deacetylases in human asthmatic airway. Am. J. Respir. Crit. Care Med. 166:392-396.

23. Bhavsar, P., Ahmad, T., and Adcock, I. 2008. The role of histone deacetylases in asthma and allergic diseases. J. Allergy Clin. Immunol. 121:580-584.

24. Su, R., Becker, A., Kozyrskyj, A., and Hayglass, K. 2008. Epigenetic regulation of established human type 1 versus type 2 cytokine responses. J. Allergy Clin. Immunol. 121:57-63.

25. Hollingsworth, J.W., et al. 2008. In utero supplementation with methyl donors enhances allergic airway disease in mice. J. Clin. Invest. 118:3462-3469.

26. Eichholze, M., Tönz, O., and Zimmermann, R. 2006. Folic acid: a public-health challenge. Lancet. 367:1352-1361.

\title{
Novel epitope begets a novel pathway in type 1 diabetes progression
}

\author{
Jeffrey A. Frelinger \\ Department of Microbiology and Immunology, University of North Carolina, Chapel Hill, North Carolina, USA.
}

\begin{abstract}
While $\mathrm{CD8}^{+} \mathrm{T}$ cells are critical to diabetogenesis in NOD mice, evidence of their involvement in human type 1 diabetes (T1D) has been circumstantial. The existence of $\mathrm{CD8}^{+} \mathrm{T}$ cells specific for $\beta$ cell peptides has been demonstrated, but functional data regarding the role of these cells in T1D have been lacking. In this issue of the JCI, Skowera et al. describe an unusual selfpeptide epitope derived from the leader sequence of preproinsulin (PPI) and show that $50 \%$ of $\mathrm{HLA}^{-\mathrm{A}^{+}}$patients with new-onset T1D possessed circulating $\mathrm{CD8}^{+} \mathrm{T}$ cells specific for this epitope, suggesting that PPI plays a critical role in the development of T1D (see the related article beginning on page 3390). They also report that $\beta$ cells upregulate PPI expression in the presence of high glucose levels, rendering these cells more susceptible to lysis and potentially accelerating disease. This suggests that interventions aimed at decreasing the PPI-specific $\mathrm{CD}^{+} \mathrm{T}$ cell response early after T1D diagnosis may be efficacious in ameliorating the disease process.
\end{abstract}

Type 1 diabetes (T1D) is an autoimmune disease that results from $\mathrm{T}$ cell-mediated destruction of the $\beta$ cells of the endocrine pancreas. Much of our knowledge about the autoimmune pathogenesis of T1D, including the role of both $\mathrm{CD}^{+}$and $\mathrm{CD}^{+}$

Nonstandard abbreviations used: PPI, preproinsulin; $\mathrm{TAP}$, transporter associated with antigen processing; T1D, type 1 diabetes.

Conflict of interest: The author has declared that no conflict of interest exists.

Citation for this article: J. Clin. Invest. 118:3268-3271 (2008). doi:10.1172/JCI37125.
$\mathrm{T}$ cells in $\beta$ cell destruction, is based on studies of the NOD mouse (1). In both mice and humans, development of T1D requires the interaction of a genetically susceptible host and an environmental insult. Investigation of the genetic basis of T1D susceptibility in NOD mice and comparison of the results with genome scans in humans with T1D have confirmed that many of the same processes are involved in this disease in both species (2). Although more than 20 loci have been described, the major genes that govern T1D susceptibility in both mice and humans map in the major histocompatibility complex. Specific MHC class II alleles in both mice and humans have a strong association with T1D susceptibility. The genetic evidence for MHC class I involvement is less clear. Removal of $\mathrm{CD}^{+} \mathrm{T}$ cells from young NOD mice results in no progression to diabetes (3). Similarly, depletion of $\mathrm{CD}^{+}{ }^{+} \mathrm{T}$ cells from NOD mice also results in the failure to progress to diabetes (4). Adoptive transfer experiments with both purified $\mathrm{T}$ cells from diabetic mice and diabetogenic $T$ cell clones established unequivocally that $\mathrm{CD} 8^{+} \mathrm{T}$ cells are critical for the development of diabetes (5). As a result, there is widespread belief that $\beta$ cell-specific immune responses mediated by both $\mathrm{CD}^{+}$and $\mathrm{CD}^{+} \mathrm{T}$ cells are required for the development of T1D in humans as well as in NOD mice. However, the evidence that $\mathrm{CD}^{+} \mathrm{T}$ cells are critical to the development of T1D in humans remains circumstantial. While $\mathrm{CD}^{+} \mathrm{T}$ cell $\beta$ cell-specific epitopes, restricted by MHC class I, have been detected, the frequency of these epitope-specific $\mathrm{CD} 8^{+} \mathrm{T}$ cell clones is low, and their in vivo function has been difficult to demonstrate (6). 


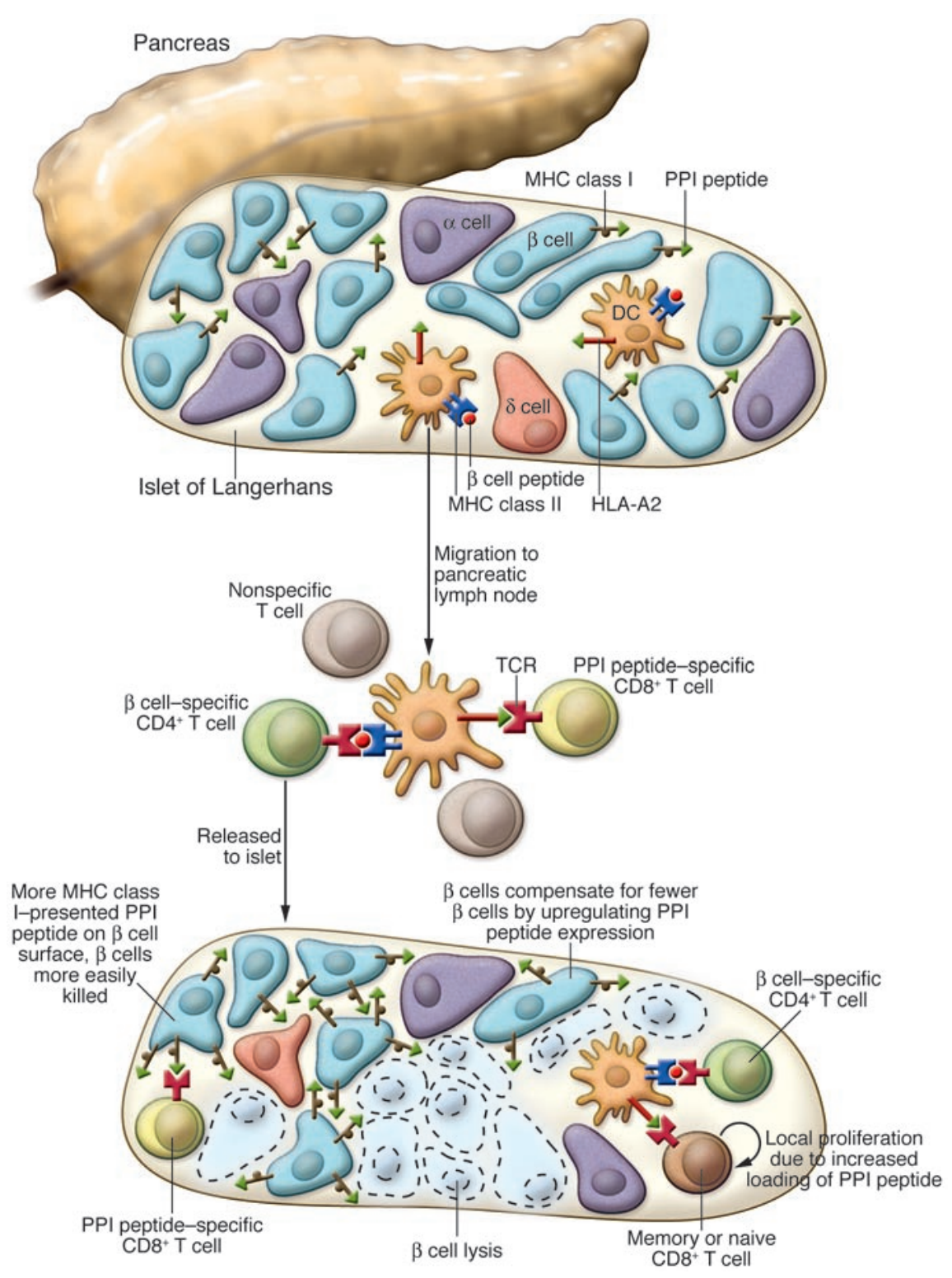

Figure 1

Model for the development of T1D, elucidating the role of PPI-specific CD8 ${ }^{+} \mathrm{T}$ cells. This image shows a schematic of an islet before the onset of T1D, with relatively low levels of PPI-derived peptides (as determined in the study in this issue of the $\mathrm{JCl}$ by Skowera et al.; ref. 7) expressed on $\beta$ cells and few or no T cells. Following migration of a dendritic cell to the draining lymph node, both $\mathrm{CD}^{+}$and $\mathrm{CD}^{+} \mathrm{T}$ cells are activated and migrate to the islets. There they encounter PPI-expressing $\beta$ cells and kill them, resulting in lowered levels of insulin and hyperglycemia, as suggested by Skowera et al. (7). This results in increased PPI production and PPI presentation on both the $\beta$ cells and resident dendritic cells. This can result in increased sensitivity to killing of $\beta$ cells by CD $8^{+}$ T cells (7), as well as in local proliferation of the effectors stimulated by resident dendritic cells.

\section{Identification of a PPI-encoded $\mathrm{CD}^{+} \mathrm{T}$ cell epitope}

In this issue of the JCI, Skowera et al. provide compelling evidence of a natural and unusual $\mathrm{CD}^{+} \mathrm{T}$ cell epitope that can be recognized on $\beta$ cells (7). The authors first constructed a novel surrogate $\beta$ cell by transfecting a cell line (K562) derived from to identify peptides that were present only from HLA-A2+ PPI-expressing K562 cells. Thus, HLA-A2-bound, PPI-derived peptides exist and are potential $T$ cell epitopes. The sequence of these HLA-A2-bound peptides was interesting, as it was derived from the leader sequence of PPI. This is not surprising, since the HLA-A2 peptidebinding motif is highly hydrophobic, as are leader sequences, and even in transporter associated with antigen processing-deficient (TAP-deficient) cells, HLA-A2 is expressed at nearly $50 \%$ of wild-type levels due to the ability of HLA-A2 to bind peptides derived from leader sequences $(8,9)$. What was more surprising was that $50 \%$ of recently diagnosed $\mathrm{HLA}-\mathrm{A} 2^{+}$patients were shown to have detectable PPI-specific CD8 ${ }^{+}$ T cell responses compared with other HLAA2-restricted responses that were found at lower frequency (7). However, it must be noted that $50 \%$ of the HLA-A2 ${ }^{+}$donors did not have detectable PPI-specific $\mathrm{CD}^{+}$ $\mathrm{T}$ cells, so other epitopes are likely to function to cause disease.

\section{PPI-specific CD8+ $\mathrm{T}$ cell clones can kill primary human $\beta$ cells}

It is not surprising that $\mathrm{CD}^{+} \mathrm{T}$ cells specific for PPI are able to lyse K562 cells expressing HLA-A2 and PPI (7). More compelling are the results using an unusual cytotoxicity assay that measures the loss of PPI mRNA. PPI-specific $\mathrm{CD}^{+} \mathrm{T}$ cell clones were able to kill primary human pancreatic $\beta$ cells in the midst of normal exocrine human pancreatic cells in vitro. This suggests that PPI-specific $\mathrm{CD}^{+} \mathrm{T}$ cell clones from T1D patients are able to recognize and kill $\beta$ cells in a contact-dependant manner. This observation regarding an MHC class Irestricted epitope derived from insulin is of significance given the finding that PPI is a critical target antigen for $\mathrm{CD}^{+} \mathrm{T}$ cells early in $\beta$ cell autoimmunity in both mice and humans $(10,11)$. The finding that two critical epitopes necessary for diabetes induction exist on a single molecule suggests that there is a good opportunity for a single dendritic cell to present PPI-derived peptides to both $\mathrm{CD}^{+}$and $\mathrm{CD} 8^{+} \mathrm{T}$ cells.

As shown in the current study, the processing pathway used for the presentation of PPI is both TAP and proteasome independent (7). Similar TAP- and proteasome-independent epitopes have previously been described in the forms of an influenza- and a tumorspecific epitope $(12,13)$. Furthermore, Skowera et al. (7) showed that PPI-producing K562 cells served as protein donors for 
indirect PPI presentation by dendritic cells that do not themselves synthesize PPI.

\section{Implications of a PPI-derived epitope}

The observations reported by Skowera et al. (7) are interesting and contribute to the identification of an epitope likely to be important in the pathogenesis of T1D. However, the most significant result of the current study is that $\beta$ cells producing increased amounts of PPI are more susceptible to lysis (7). This makes sense if the PPI peptide is limiting in either the priming of $\mathrm{CD}^{+} \mathrm{T}$ cells or in $\beta$ cell sensitivity to lysis by PPI-specific $\mathrm{CD}^{+} \mathrm{T}$ cells. What is diabolical about this result is that following the initial phases of $\beta$ cell destruction, the remaining $\beta$ cells produce more PPI in an effort to compensate for lowered levels of insulin. It is this increase in PPI production by $\beta$ cells that results in the more rapid destruction of the remaining $\beta$ cells and, presumably, increased antigen presentation by resident dendritic cells and increased PPI-specific $\mathrm{CD}^{+} \mathrm{T}$ cell activation. Indeed, increased activation might not even be limited to PPI-specific CD8 ${ }^{+} \mathrm{T}$ cells, since the increased production of TNF- $\alpha$ by the PPIspecific $\mathrm{CD}^{+} \mathrm{T}$ cells will promote maturation of dendritic cells and could well result in epitope spreading, whereby $\beta$ cell proteins different from PPI would stimulate new autoimmune $\mathrm{CD}^{+}$and $\mathrm{CD}^{+} \mathrm{T}$ cell responses. This would create an out-ofcontrol autoimmune response directed at not only PPI but other $\beta$ cell antigens. This model is shown in Figure 1.

This model raises the question of what is the initial inciting event that triggers the PPI-specific $\mathrm{CD}^{+} \mathrm{T}$ cell response? Neither does it explain the critical requirement for specific MHC class II alleles for T1D susceptibility or the ability of other MHC class II alleles to be protect against development of T1D (14). The necessity for a CD4 ${ }^{+} \mathrm{T}$ cell response has been established conclusively in the mouse, and the MHC class II association with T1D in humans argues strongly for it. In both mice and humans, MHC class IIrestricted responses to GAD65 have been demonstrated (6). $\mathrm{CD}^{+} \mathrm{T}$ cells specific for GAD65 are critical to the pathogenesis of T1D (15). Future experiments in which those PPI-specific responses are ablated by the induction of tolerance would be important in order to support the idea of halting the early autoimmune response and thus blocking the downstream consequences. Thus, the elegant experiments reported in the current study do not address the cru- cial interaction between $\mathrm{CD}^{+}$and $\mathrm{CD}^{+}$ $\mathrm{T}$ cells. The study leaves unexamined the critical questions regarding the specificity of the MHC class II-restricted epitopes and where antigen presentation occurs. This last question is of considerable importance. Since only $\beta$ cells produce significant quantities of PPI and $\beta$ cells do not express MHC class II, the presentation must occur via a cross-priming pathway. As shown by the authors, cross-priming does occur, but where is the presented PPI peptide processed? In the ER of the $\beta$ cell? As PPI presentation seems to be both TAP and proteasome independent, how does the PPI peptide get from the ER of the $\beta$ cell where it is produced to the surface of the dendritic cell? Recently, Unanue and colleagues have demonstrated the existence of a small number of dendritic cells in the islets of mice (16). These cells were shown to circulate to the draining lymph node and were able to present both a model antigen as well as an authentic $\beta$ cell autoantigen to $\mathrm{CD}^{+} \mathrm{T}$ cells. Both of these responses are $\mathrm{MHC}$ class II restricted and so do not provide information on MHC class I-restricted responses. Given the data presented by Skowera et al. (7) that demonstrate the ability of dendritic cells to present both PPI and $\beta$ cell antigen, this provides a plausible route of stimulation, although many of the steps remain to be elucidated.

Still to be defined is the role of antigen presentation in the islets. Lymphoid structures similar to lymph nodes have been described in the islets of autoimmune mice $(17,18)$. The role of these structures in diabetogenesis is not clear, but the concept of antigen presentation by resident dendritic cells is attractive, and the process would not require trafficking of the resident dendritic cell to the pancreatic lymph node.

Further, the experiments reported here do not address the question of the involvement of Tregs, which have been shown to be important for the development of diabetes in NOD mice (19). This critical question remains to be addressed in the future. Finally, this model is unable to explain why $50 \%$ of HLA-A2 ${ }^{+}$T1D patients showed no detectable response to PPI. Other $\beta$ cell antigens could play the same role, or, alternatively, PPI-specific $\mathrm{CD}^{+} \mathrm{T}$ cell responses could have waned over time in these individuals.

The high level of association between the PPI-specific $\mathrm{CD}^{+} \mathrm{T}$ cell response in HLA$\mathrm{A} 2^{+}$individuals and T1D in recently diagnosed patients suggests that measurement of this response may prove to be of addi- tional utility as a biomarker. Biomarkers have the potential to identify individuals at increased risk of disease. The PPI-specific $\mathrm{CD}^{+} \mathrm{T}$ cell response is a candidate for such a marker, since the response to PPI must precede the destruction of $\beta$ cells and would be expected to become more robust as the prediabetic phase continues.

Perhaps most telling is that this model of the diabetogenic response presents a clear window of opportunity for treating patients. Conventional wisdom tells us not to treat T1D patients with insulin when their own $\beta$ cells are able to produce sufficient insulin. The results presented here suggest just the opposite (7). Increased insulin production by the surviving $\beta$ cells would accelerate disease pathogenesis and $\beta$ cell destruction. Aggressive treatment with insulin for the purpose of inducing tolerance would be predicted to slow disease and perhaps block its progression.

\section{Acknowledgments}

I thank Roland Tisch, Bo Wang, and Ellen Young for discussion and comments on drafts of this commentary. The author is supported by grants from the NIH (AI52435 and AI058014) and the Juvenile Diabetes Research Foundation.

Address correspondence to: Jeffrey A. Frelinger, Department of Microbiology and Immunology, CB 7290 Jones, University of North Carolina, Chapel Hill, North Carolina 27599-7290, USA. Phone: (919) 9662599; Fax: (919) 962-8103; E-mail: jfrelin@ med.unc.edu.

1. Giarratana, N., Penna, G., and Adorini, L. 2007. Animal models of spontaneous autoimmune disease: type 1 diabetes in the nonobese diabetic mouse. Methods Mol. Biol. 380:285-311.

2. Wicker, L.S., et al. 2005. Type 1 diabetes genes and pathways shared by humans and NOD mice. J. Autoimmun. 25(Suppl.):29-33.

3. Wang, B., Gonzalez, A., Benoist, C., and Mathis, D. 1996. The role of CD8 $+\mathrm{T}$ cells in the initiation of insulin-dependent diabetes mellitus. Eur. J. Immunol. 26:1762-1769.

4. Shizuru, J.A., Taylor-Edwards, C., Banks, B.A., Gregory, A.K., and Fathman, C.G. 1988. Immunotherapy of the nonobese diabetic mouse: treatment with an antibody to T-helper lymphocytes. Science. 240:659-662.

5. Mallone, R., and van Endert, P. 2008. T cells in the pathogenesis of type 1 diabetes. Curr. Diab. Rep. 8:101-106.

6. Di Lorenzo, T.P., Peakman, M., and Roep, B.O. 2007. Translational mini-review series on type 1 diabetes: systematic analysis of $\mathrm{T}$ cell epitopes in autoimmune diabetes. Clin. Exp. Immunol. 148:1-16.

7. Skowera, A., et al. 2008. CTLs are targeted to kill $\beta$ cells in patients with type 1 diabetes through recognition of a glucose-regulated preproinsulin epitope. J. Clin. Invest. 118:3390-3402.

8. Henderson, R.A., et al. 1992. HLA-A2.1-associated 
peptides from a mutant cell line: a second pathway of antigen presentation. Science. 255:1264-1266.

9. Wei, M.L., and Cresswell, P. 1992. HLA-A2 molecules in an antigen-processing mutant cell contain signal sequence-derived peptides. Nature. 356:443-446.

10. Kent, S.C., et al. 2005. Expanded T cells from pancreatic lymph nodes of type 1 diabetic subjects rec ognize an insulin epitope. Nature. 435:224-228.

11. Nakayama, M., et al. 2005. Prime role for an insulin epitope in the development of type 1 diabetes in NOD mice. Nature. 435:220-223.

12. Gueguen, M., Biddison, W.E., and Long, E.O. 1994. T cell recognition of an HLA-A2-restricted epitope derived from a cleaved signal sequence. J. Exp. Med.
180:1989-1994.

13. Wolfel, C., et al. 2000. Transporter (TAP)- and proteasome-independent presentation of a melanoma-associated tyrosinase epitope. Int. J. Cancer. 88:432-438.

14. McDevitt, H.O. 1998. The role of MHC class II molecules in susceptibility and resistance to autoimmunity. Curr. Opin. Immunol. 10:677-681.

15. Goudy, K.S., and Tisch, R. 2005. Immunotherapy for the prevention and treatment of type 1 diabetes. Int. Rev. Immunol. 24:307-326.

16. Calderon, B., Suri, A., Miller, M.J., and Unanue, E.R. 2008. Dendritic cells in islets of Langerhans constitutively present beta cell-derived peptides bound to their class II MHC molecules. Proc. Natl. Acad. Sci. U. S. A. 105:6121-6126.

17. Kendall, P.L., Yu, G., Woodward, E.J., and Thomas, J.W. 2007. Tertiary lymphoid structures in the pancreas promote selection of B lymphocytes in autoimmune diabetes. J. Immunol. 178:5643-5651.

18. Ludewig, B., Odermatt, B., Landmann, S., Hengartner, H., and Zinkernagel, R.M. 1998. Dendritic cells induce autoimmune diabetes and maintain disease via de novo formation of local lymphoid tissue. J. Exp. Med. 188:1493-1501.

19. Tang, Q., et al. 2004. In vitro-expanded antigenspecific regulatory $\mathrm{T}$ cells suppress autoimmune diabetes. J. Exp. Med. 199:1455-1465

\title{
Coaxing the liver into preventing autoimmune disease in the brain
}

\author{
Brad E. Hoffman and Roland W. Herzog
}

Department of Pediatrics, University of Florida, Gainesville, Florida, USA.

\begin{abstract}
The liver has several unique immunological properties that affect $T$ cell activation and immune regulation. Recent studies have uncovered opportunities for the treatment of genetic disease by directing expression of the functional therapeutic protein to hepatocytes. In a new study in this issue of the JCI, Lüth and colleagues demonstrate that hepatic expression of a brain protein is protective against neuroinflammatory disease in a mouse model of human MS (see the related article beginning on page 3403). Suppression of autoimmunity was dependent on transgene expression in the liver and was mediated by induction of antigen-specific $\mathrm{CD}^{+} \mathrm{CD}^{+} 5^{+} \mathrm{Foxp} 3^{+}$Tregs. These findings suggest that the introduction of antigens to the liver may have potential as a preventative or therapeutic intervention for autoimmune disease.
\end{abstract}

Immune responses are substantially influenced by the context of the tissue in which they occur. For example, brain and liver have both been characterized as immuneprivileged sites. The liver is constantly exposed to food antigens and therefore must control inflammatory responses to exogenous antigens. Furthermore, injection of antigen into the portal vein can induce tolerance, and spontaneous acceptance of liver allograft accompanied by donor-specific $\mathrm{T}$ cell tolerance has been documented previously (1). The immune system in the brain parenchyma lacks dendritic cells and therefore the ability to prime $\mathrm{T}$ cells. However, $\mathrm{T}$ cell activation upon immunization at an ectopic site can cause lymphocyte infiltration and inflam-

Nonstandard abbreviations used: MBP, myelin basic protein.

Conflict of interest: The authors have declared that no conflict of interest exists.

Citation for this article: J. Clin. Invest. 118:3271-3273 (2008). doi:10.1172/JCI37079. matory responses targeting antigens in the brain (2). For example, immunization against myelin basic protein (MBP) - a protein important in the process of nerve myelination - causes EAE in certain strains of mice, and these animals have been used as a model for human MS.

On the other hand, it is also known that antigen administration to specific organs can induce suppressive immune responses that ultimately promote tolerance. Oral and nasal tolerance are extensively studied scenarios in which antigen introduced to mucosal surfaces at optimal doses causes activation of Tregs such as $\operatorname{Tr} 1$ or Th 3 cells (3-5). These subsets of CD4 ${ }^{+} \mathrm{T}$ cells can suppress immune responses by secretion of the cytokines IL-10 and TGF- $\beta$. Similarly, antigen administered to the anterior chamber of the eye, another immune-privileged site, is transported to the spleen via a macrophage-like F4/80+ cell (6). Antigen presentation by this cell type in the lymphoid tissue causes activation of $\mathrm{CD}^{+}$and $\mathrm{CD}^{+}$ Tregs and NKT cells, resulting in immune suppression. These examples illustrate how the immune system has evolved to generate cellular mediators of tolerance, which are exposed to antigens in the context of one organ and are capable of subsequently transferring tolerance to a different organ.

\section{Gene transfer to the liver induces immune tolerance}

The question of how to establish immune tolerance is critical for gene- and cell-based therapies for genetic and autoimmune diseases. Interestingly, a number of reports in recent years have shown that hepatic gene transfer can induce tolerance to a variety of therapeutic proteins (7-13). While there has been evidence of deletion and anergy of transgene product-specific $T$ cells following hepatocyte-derived gene expression, a finding key to our understanding of the mechanism of tolerance induction was the observation of $\mathrm{CD}^{+}$Treg activation (14-16). Using a $\mathrm{T}$ cell receptor transgenic model, the induction of antigen-specific $\mathrm{CD}^{+} \mathrm{CD} 25^{+} \mathrm{Foxp}^{+} \mathrm{T}$ cells by liver-directed gene transfer with an adeno-associated viral vector has been previously demonstrated (14). These induced T cells appeared phenotypically comparable to naturally occurring Tregs, which are required to prevent autoimmune disease. In other experiments, Tregs induced by hepatic adeno-associated viral gene transfer were capable of suppressing antibody formation and $\mathrm{CD}^{+}$ $T$ cell responses against a coagulation Factor IX gene product and were found to be required for tolerance induction $(14,17)$. 